\title{
Cadherin-mediated Intercellular Adhesion and Signaling Cascades Involving Small GTPases
}

\author{
Takashi Watanabe ${ }^{1,2}$, Kazuhide Sato ${ }^{1}$, and Kozo Kaibuchi ${ }^{1,3}$ \\ ${ }^{1}$ Department of Cell Pharmacology, Nagoya University Graduate School of Medicine, 65 Tsurumai, \\ Showa, Nagoya 466-8550, Japan \\ ${ }^{2}$ Institute for Advanced Research, Nagoya University, Furo, Showa, Nagoya 464-8601, Japan \\ ${ }^{3}$ JST, CREST, 4-1-8 Honcho, Kawaguchi 332-0012, Japan \\ Correspondence: kaibuchi@med.nagoya-u.ac.jp
}

Epithelia form physical barriers that separate the internal milieu of the body from its external environment. The biogenesis of functional epithelia requires the precise coordination of many cellular processes. One of the key events in epithelial biogenesis is the establishment of cadherin-dependent cell-cell contacts, which initiate morphological changes and the formation of other adhesive structures. Cadherin-mediated adhesions generate intracellular signals that control cytoskeletal reorganization, polarity, and vesicle trafficking. Among such signaling pathways, those involving small GTPases play critical roles in epithelial biogenesis. Assembly of E-cadherin activates several small GTPases and, in turn, the activated small GTPases control the effects of E-cadherin-mediated adhesions on epithelial biogenesis. Here, we focus on small GTPase signaling at E-cadherin-mediated epithelial junctions.

\begin{abstract}
Cell-cell adhesions are involved in a diverse
range of physiological processes, including morphological changes during tissue development, cell scattering, wound healing, and synaptogenesis (Adams and Nelson 1998; Gumbiner 2000; Halbleib and Nelson 2006; Takeichi 1995; Tepass et al. 2000). In epithelial cells, cell-cell adhesions are classified into three kinds of adhesions: adherens junction, tight junction, and desmosome (for more details, see Meng and Takeichi 2009, Furuse 2009, and Delva et al. 2009, respectively). A key event in epithelial polarization and biogenesis is the establishment of cadherin-dependent cell-cell contacts. Cadherins belong to a large
\end{abstract}

family of adhesion molecules that require $\mathrm{Ca}^{2+}$ for their homophilic interactions (Adams and Nelson 1998; Blanpain and Fuchs 2009; Gumbiner 2000; Hartsock and Nelson 2008; Takeichi 1995; Tepass et al. 2000). Cadherins form transinteraction on the surface of neighboring cells (for details, see Shapiro and Weis 2009). For the development of strong and rigid adhesions, cadherins are clustered concomitantly with changes in the organization of the actin cytoskeleton (Tsukita et al. 1992). Classical cadherins are required, but not sufficient, to initiate cell-cell contacts, and other adhesion protein complexes subsequently assemble (for details, see Green et al. 2009).

Editors: W. James Nelson and Elaine Fuchs

Additional Perspectives on Cell Junctions available at www.cshperspectives.org

Copyright (C) 2009 Cold Spring Harbor Laboratory Press; all rights reserved; doi: 10.1101/cshperspect.a003020

Cite this article as Cold Spring Harb Perspect Biol 2009;1:a003020 
These complexes include the tight junction, which controls paracellular permeability, and desmosomes, which support the structural continuum of epithelial cells. A fundamental problem is to understand how these diverse cellular processes are regulated and coordinated. Intracellular signals, generated when cells attach with one another, mediate these complicated processes.

Several signaling pathways upstream or downstream of cadherin-mediated cell-cell adhesions have been identified (Perez-Moreno et al. 2003) (see also McCrea et al. 2009). Among these pathways, small GTPases including the Rho and Ras family GTPases play critical roles in epithelial biogenesis and have been studied extensively. Many key morphological and functional changes are induced when these small GTPases act at epithelial junctions, where they mediate an interplay between cell-cell adhesion molecules and fundamental cellular processes including cytoskeletal activity, polarity, and vesicle trafficking. In addition to these small GTPases, $\mathrm{Ca}^{2+}$ signaling and phosphorylation of cadherin complexes also play pivotal roles in the formation and maintenance of cadherin-mediated adhesions. Here, we focus on signaling pathways involving the small GTPases in E-cadherin-mediated cell-cell adhesions. Other signaling pathways are described in recent reviews (Braga 2002; Fukata and Kaibuchi 2001; Goldstein and Macara 2007; McLachlan et al. 2007; Tsukita et al. 2008; Yap and Kovacs 2003; see also McCrea et al. 2009).

\section{MODE OF ACTION OF THE SMALL GTPases}

Small GTPases have GDP/GTP binding and GTPase activity. They cycle between a GTPbound active state and a GDP-bound inactive state, thus functioning as molecular switches in cells (Fig. 1). The nucleotide state of the small GTPases is generally controlled by three

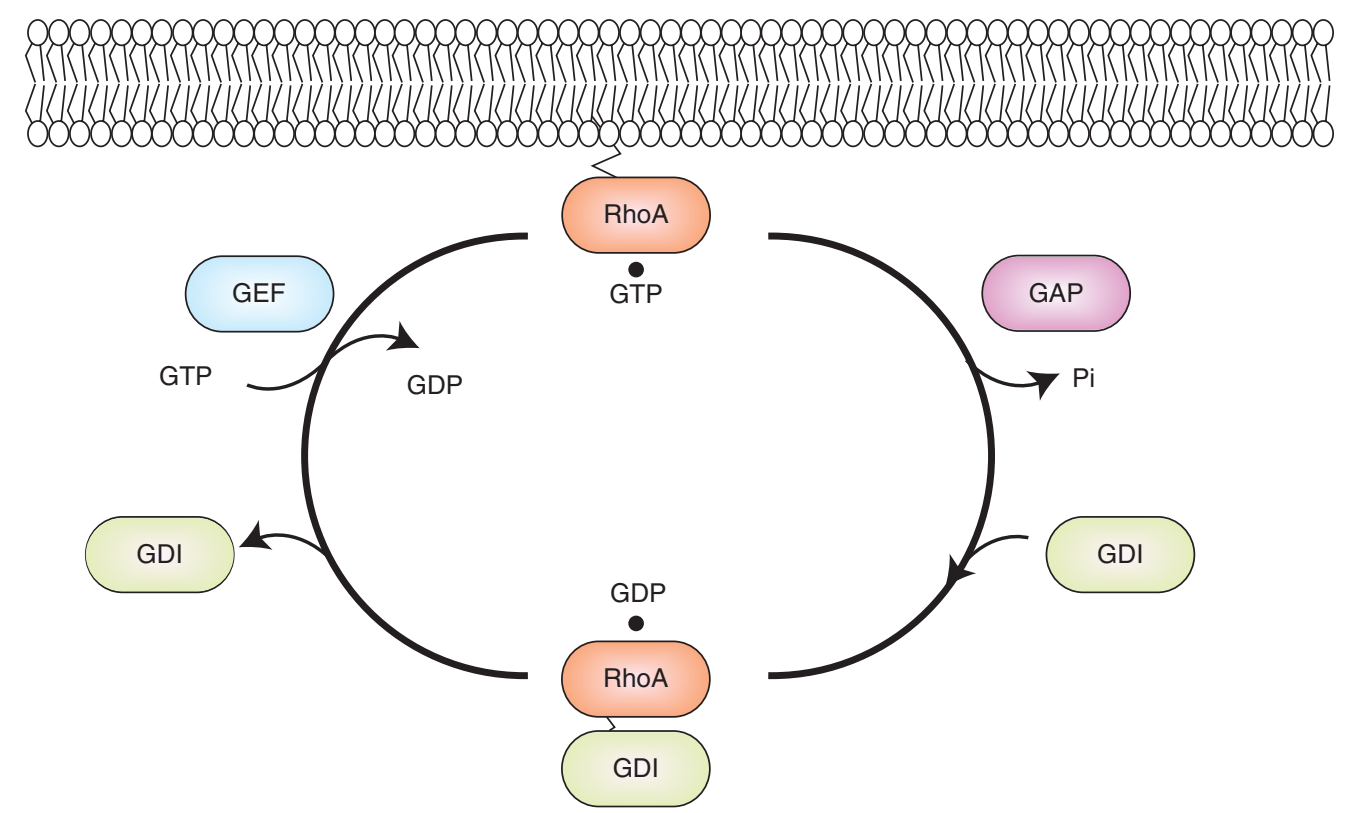

Figure 1. Regulation of the small GTPases. In this figure, RhoA is depicted. In resting cells, Rho exists mostly in the GDP-bound form (GDP. Rho) and in complexes with Rho GDIs in the cytosol. On stimulation with extracellular signals, Rho is likely to be dissociated from Rho GDIs and targeted to specific membranes by its carboxy-terminal prenyl group. At the membrane, specific GEFs for Rho are activated: GDP. Rho is then converted to GTP. Rho. GTP. Rho interacts with its specific effectors and exerts its functions. GAPs enhance the GTPase activity of Rho and reconvert Rho to its inactive GDP-bound form. Rho GDI can then form a complex with GDP. Rho and extract it from the membrane back into the cytosol. 
classes of key regulators: Guanine nucleotide exchange factors (GEFs), which promote the exchange of GDP for GTP; GDP dissociation inhibitors (GDIs), which interact with GDPbound small GTPases, inhibit the exchange of GDP for GTP, and sequester the small GTPases into the cytosol (note that a GDI for the Ras family has not been identified); and GTPase-activating proteins (GAPs), which enhance the intrinsic GTPase activity of small GTPases. These regulators ensure that activation and inactivation of small GTPases is tightly regulated both spatially and temporally in order to generate specific and localized effects (Gulli and Peter 2001; Jaffe and Hall 2005; Kaibuchi et al. 1999; Van Aelst and D'souza-Schorey 1997). The modes of action of small GTPases have been elucidated by the identification and characterization of specific effectors. Such effector molecules interact with small GTPases only in their GTP-bound state to transmit signals downstream and exert physiological functions (Gulli and Peter 2001; Jaffe and Hall 2005; Kaibuchi et al. 1999; Van Aelst and D'souza-Schorey 1997).

The Rho family GTPases are believed to shuttle between the cytosol and specific membrane sites after extracellular stimulation (Fleming et al. 1996; Kranenburg et al. 1997). In epithelial cells, Rac1 and Cdc42, which are members of the Rho family GTPases, localize to sites of cell-cell junctions (Jou and Nelson 1998; Kuroda et al. 1998; Nakagawa et al. 2001; Takaishi et al. 1997). In Madin-Darby canine kidney II (MDCKII) cells, Rac1 is colocalized with E-cadherin at sites of cell-cell contact and is translocated to the cytosol during disruption of cell-cell adhesion by $\mathrm{Ca}^{2+}$ chelation with EGTA (Nakagawa et al. 2001). Furthermore, studies using green fluorescent protein (GFP) show that an anti-Ecadherin antibody or the functional extracellular domain of E-cadherin fused to Fc region can recruit Racl-GFP immediately at contact sites (Kovacs et al. 2002; Nakagawa et al. 2001; Niessen and Gumbiner 2002; Perez et al. 2008). Racl is also colocalized to E-cadherincontaining vesicles in keratinocytes (Akhtar and Hotchin 2001). Cdc42 is found at sites of cell-cell contact as well as the Golgi apparatus (Kroschewski et al. 1999), where it is thought to regulate the establishment of epithelial polarity during secretory and endocytic vesicle transport. On the other hand, RhoA, another member of the Rho family GTPases, localizes diffusely in the cytosol (Takaishi et al. 1997). Rap1, a member of the Ras family GTPases, accumulates at sites of cell-cell contact in an activity-independent manner. Similar to the case of Rac1, E-cadherin-Fc can recruit Rap1 to the plasma membrane (Hogan et al. 2004).

Several regulators of small GTPases accumulate at the site of cell-cell contacts through PDZ (PSD-95, Dlg, and ZO-1) domainmediated interactions. $\beta$-catenin possesses a PDZ-binding consensus sequence at its carboxyl terminus and can recruit several PDZ domain-containing scaffolding and signaling molecules (Dobrosotskaya and James 2000; Ide et al. 1999; Kawajiri et al. 2000; Perego et al. 2000). PDZ domain-containing GEFs for small GTPases have also been shown to localize to intercellular adhesion sites. These GEFs include Tiam1 (Michiels et al. 1995), STEF (Hoshino et al. 1999), PDZ-RhoGEF (Fukuhara et al. 1999), and LARG (Kourlas et al. 2000; Taya et al. 2001). This localization of GEFs may account for the activation of the Rho family GTPases at intercellular adhesion sites (see the following).

The function of small GTPases is investigated with the use of three kinds of tools: point mutants of small GTPases to serve as constitutively active and dominant negative forms, affinity precipitation with a specific effector to monitor the level of activated small GTPases, and FRET (fluorescence resonance energy transfer)-based imaging techniques to show the spatiotemporal activation states of small GTPases. These biosensors provide valuable insights because small GTPases are activated separately in space and time within a single epithelial cell. Recent RNAibased methods and the availability of knockout mice provide additional approaches to examine effects of the loss of function of small GTPases. These tools have increased our understanding of the roles of small GTPases in 
epithelial as well as nonepithelial cells, such as fibroblasts and neuronal cells (Braga and Yap 2005; Fukata and Kaibuchi 2001; Kiyokawa et al. 2006; Pertz and Hahn 2004; Van Aelst and Symons 2002).

\section{DE NOVO CADHERIN-MEDIATED ADHESIONS CONTROL THE ACTIVITY OF SMALL GTPases}

Like stimulation by growth factors, the engagement of integrins with fibronectin induces the activation of small GTPases (Price et al. 1998). Analogies with integrin-mediated cellsubstratum adhesions lead to the speculation that cadherins might also function as receptors that transduce signals to small GTPases (outsidein-signal) (Table 1). Indeed, E-cadherinmediated cell-cell interactions result in the rapid activation of Cdc42 in MCF-7 epithelial cells (Kim et al. 2000). Homophilic E-cadherin ligations recruit Racl at adhesion sites and induce its activation in MDCKII cells, and basal levels of active Racl are still maintained even when cells become confluent (Betson et al. 2002; Braga et al. 1997; Nakagawa et al. 2001; Noren et al. 2001). These findings raise the question of how cadherin-mediated cell-cell adhesions modulate the activity of Rho family GTPases. It has been reported that E-cadherin-mediated cellcell adhesions stimulate phosphatidylinositol 3-kinase (PI3K) activity in MDCKII cells (Pece et al. 1999). Moreover, PI3K has been shown to interact with E-cadherin (Pece et al. 1999) and $\beta$-catenin (Espada et al. 1999). Because PI3K is thought to function upstream of Racl (Kotani et al. 1994), these observations indicate the possible involvement of
PI3K in E-cadherin-dependent Racl activation. Indeed, wortmannin - an inhibitor of PI3Kinhibits E-cadherin-induced Racl activation but does not affect the localization of Racl or E-cadherin (Nakagawa et al. 2001).

Activation of Rac1 through PI3K by Ecadherin-mediated cell-cell adhesions seems to require at least two steps (Fig. 2): (1) Rac1 recruitment to sites of cell-cell contacts, and (2) Racl activation by a GEF that responds to PI3K products. Consistently, Rac1 rapidly accumulates at the sites of E-cadherin engagement $(1-3 \mathrm{~min})$, and this accumulation is independent of Racl GTP binding/hydrolysis (Perez et al. 2008). Considering that Tiam1 is localized at sites of cell-cell contacts and functions downstream of PI3K, Tiam1 appears to act as a Rac1 GEF that functions downstream of E-cadherin engagement. Another possible mechanism for the regulation of Rho family GTPases involves p120ctn, which binds directly to the juxtamembrane domain of E-cadherin. p120ctn likely activates Rac1 and Cdc42 and inhibits RhoA. Vav2, a RhoGEF, directly binds to p120ctn, which may account for the ability of p120ctn to activate Rac1 and Cdc42 (Noren et al. 2000). Because Racl antagonizes RhoA through a mechanism that involves p190 RhoGAP, it is possible that the inhibition of RhoA by p120ctn occurs indirectly through the activation of Rac1 (Bustos et al. 2008; Nimnual et al. 2003). However, it remains controversial how p120ctn regulates Rho family GTPases (Anastasiadis 2007; Reynolds 2007; Wildenberg et al. 2006).

RhoA is also activated during calciuminduced keratinocyte differentiation (Calautti et al. 2002). Localization of Racl and RhoA activity using FRET biosensors shows

Table 1. Activation of small GTPases by cadherin

\begin{tabular}{|c|c|c|c|c|c|}
\hline Small GTPase & E-cadherin & $\mathrm{N}$-cadherin & VE-cadherin & R-cadherin & C-cadherin \\
\hline $\mathrm{Cdc} 42$ & $+(\mathrm{MCF}-7)$ & - & + & $-/+$ & - \\
\hline Rac1 & + & - & + & + & + \\
\hline RhoA & + & + & - & - & - \\
\hline Rap1 & + & ND & + & ND & ND \\
\hline
\end{tabular}

Activation of small GTPases by various cadherins. Increased levels of activated Cdc42, Rac1, RhoA, and Rap1 are assessed by biochemical or FRET-based methods. (ND) not determined; (+) activated; (-) not activated. 


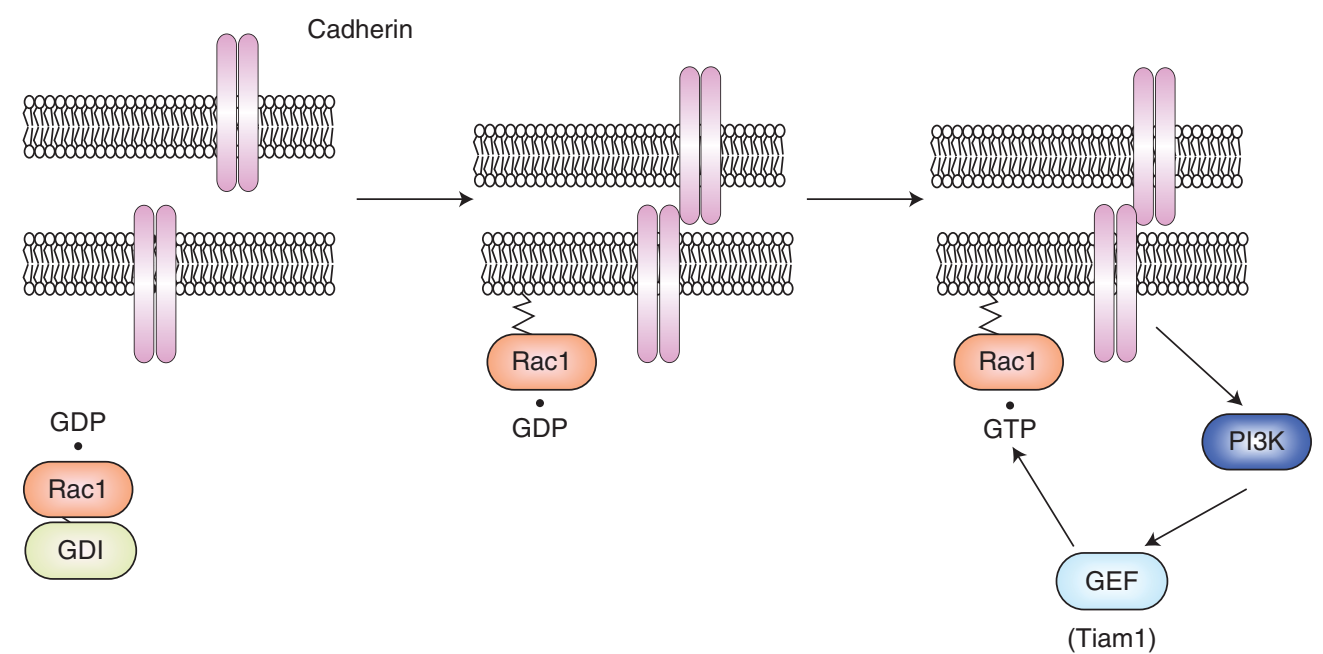

Figure 2. Mode of activation of Racl by the formation of E-cadherin-mediated cell-cell adhesions. Before the establishment of E-cadherin-mediated cell-cell adhesions, GDP. Racl is sequestered in the cytosol by Rho GDI. When cadherin-mediated homophilic interactions occur, GDP. Rac1 is dissociated from Rho GDI by an unknown mechanism and is targeted to the plasma membrane. GDP. Rac1 is converted to GTP. Rac1 through the action of a GEF (e.g., Tiam1) downstream of PI3k. Activated Racl then positively regulates E-cadherin-mediated cell-cell adhesions.

spatiotemporal activation during the initiation and expansion of epithelial cell-cell junctions (Yamada and Nelson 2007). The zones of Racl and lamellipodia activity as well as those of RhoA and actomyosin contractility are restricted to the periphery of the contacting membranes and together drive the initiation, expansion, and completion of cell-cell adhesions. These observations are consistent with the proposal that $\mathrm{Racl} / \mathrm{Cdc} 42$ and RhoA exert mutually antagonistic effects at some point during contact initiation, maturation, and reorganization, as in the case of the formation of focal adhesions (Rottner et al. 1999) and neurite extension (Kozma et al. 1997). It has also been shown that Tiam1 or constitutively active Rac1 (Rac1V12) can down-regulate RhoA activity and revert the mesenchymal phenotype of RasV12-transformed MDCKII cells to an epithelial phenotype (Sander et al. 1999). Thus, E-cadherin-mediated adhesions activate Rac1 and Cdc42, and active Rac1 downregulates RhoA spatially, possibly through certain types of Rho GAPs, such as p190 RhoGAP (Bustos et al. 2008; Nimnual et al. 2003; Wildenberg et al. 2006).
Rap1 is activated by many extracellular stimuli and is strongly implicated in the control of integrin-mediated cell adhesions. Recent evidence indicates that Rap1 also plays key roles in the formation of cadherin-based cell-cell adhesions (Fig. 3) (Kooistra et al. 2007; Retta et al. 2006). Rap1 is activated by homophilic E-cadherin ligation (Hogan et al. 2004). This Rap 1 activation is required for subsequent Cdc42 activation. Interestingly, Rap1 GEFs such as PDZ-GEF1 and C3G are linked to cadherin directly and indirectly, respectively, and contribute to Rap1 activation (Hogan et al. 2004; Kawajiri et al. 2000; Sakurai et al. 2006). Hogan and colleagues (2004) found that C3G binds to the cadherin cytoplasmic tail, providing a potential mechanism for E-cadherin to locally activate Rap1. Furthermore, C3G has been implicated in activating Rap1 downstream of the junctional protein nectin. In this case, C3G requires activation of Src after nectin clustering. It should be noted that nectin-based adhesions sequentially activate Rap1, Cdc42, and Rac1 (Fukuhara et al. 2004; Fukuyama et al. 2005; Kawakatsu et al. 2005; Kawakatsu et al. 2002). 
T. Watanabe, K. Sato, and K. Kaibuchi

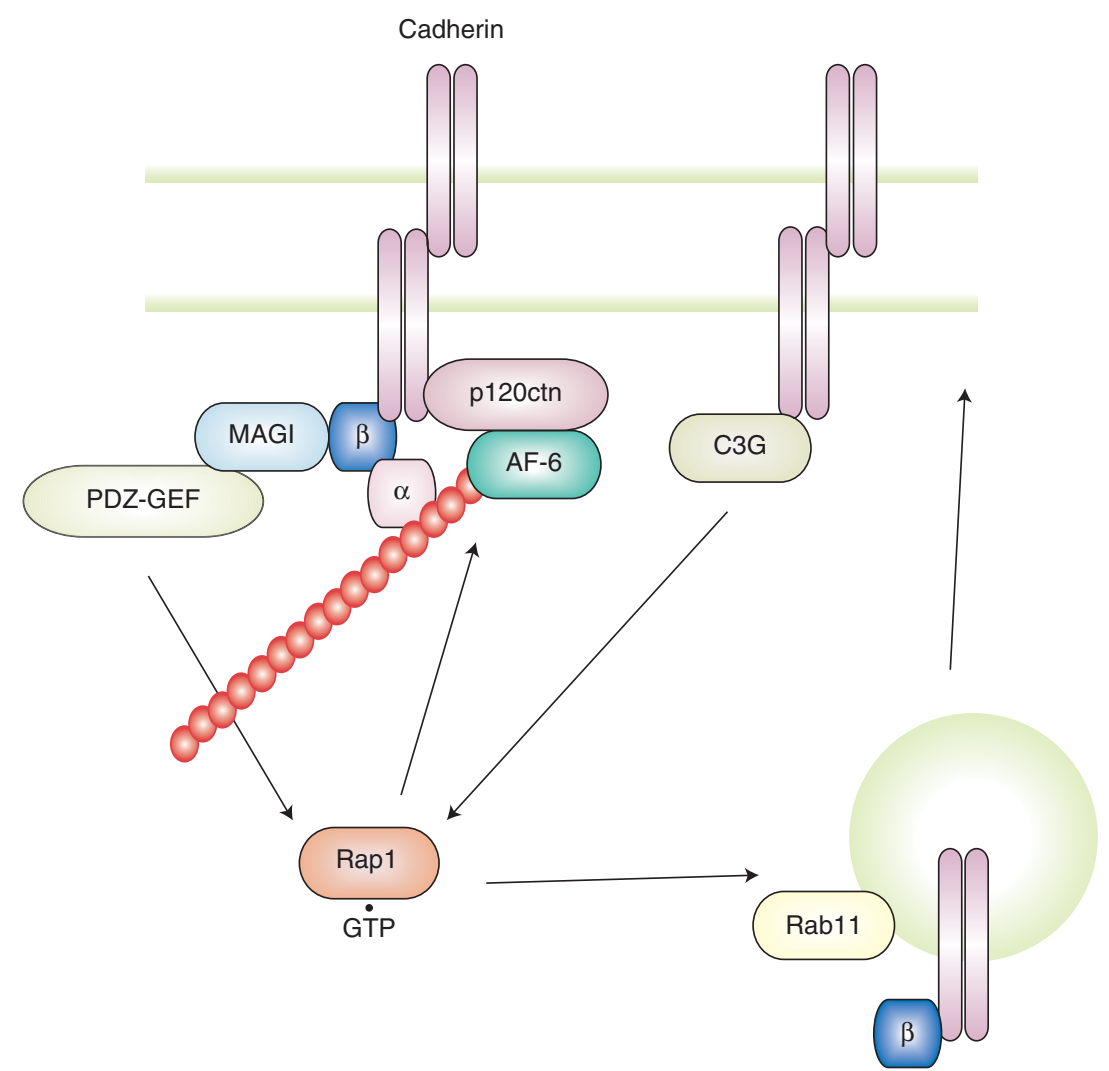

Figure 3. Model for the mode of action of Rap1 at cell-cell junctions. At initial cell-cell contacts, C3G bound to E-cadherin activates Rap1. Alternatively, PDZ-GEF linked to E-cadherin through MAGI and $\beta$-catenin can activate Rap1. Rap1 is also activated during E-cadherin endocytosis and locates to the E-cadherin/ Rab11-containing vesicles. This population is likely involved in E-cadherin trafficking.

Additionally, cAMP analogues can influence cadherin-mediated adhesions in a Rap1dependent manner, suggesting that a cAMPresponsible Rap1GEF, EPAC, is involved in signaling from cadherins (Price et al. 2004; Wittchen et al. 2005).

Thus, E-cadherin-mediated cell-cell contacts activate small GTPases including Rac1, Cdc42, and Rap1. However, it remains elusive how E-cadherin spatially and temporally regulates these small GTPases.

\section{SMALL GTPases REGULATE ESTABLISHED ADHERENS JUNCTIONS}

When small GTPases are activated by Ecadherin-mediated cell-cell contacts, they control existing E-cadherin-mediated adhesions (inside-out-signal) (Fig. 4). Braga and colleagues (Braga et al. 1997) found that the Rho family GTPases affect the formation of cell-cell junctions. When dominant-negative Rac1 (Rac1N17) or C3 botulinum toxin (an inhibitor of RhoA by ADP-ribosylation) is microinjected into keratinocytes, cadherin accumulation is inhibited at sites of cell-cell contacts. Subsequent studies from Takaishi and colleagues (1997) revealed that overexpression of constitutively active Rac1 (Rac1V12) in MDCKII cells promotes basal accumulation of E-cadherin, $\beta$-catenin, and actin filaments at sites of cell-cell contacts, whereas overexpression of Rac1N17 reduces their accumulation. Moreover, Cdc42, as well as Rac1, is 


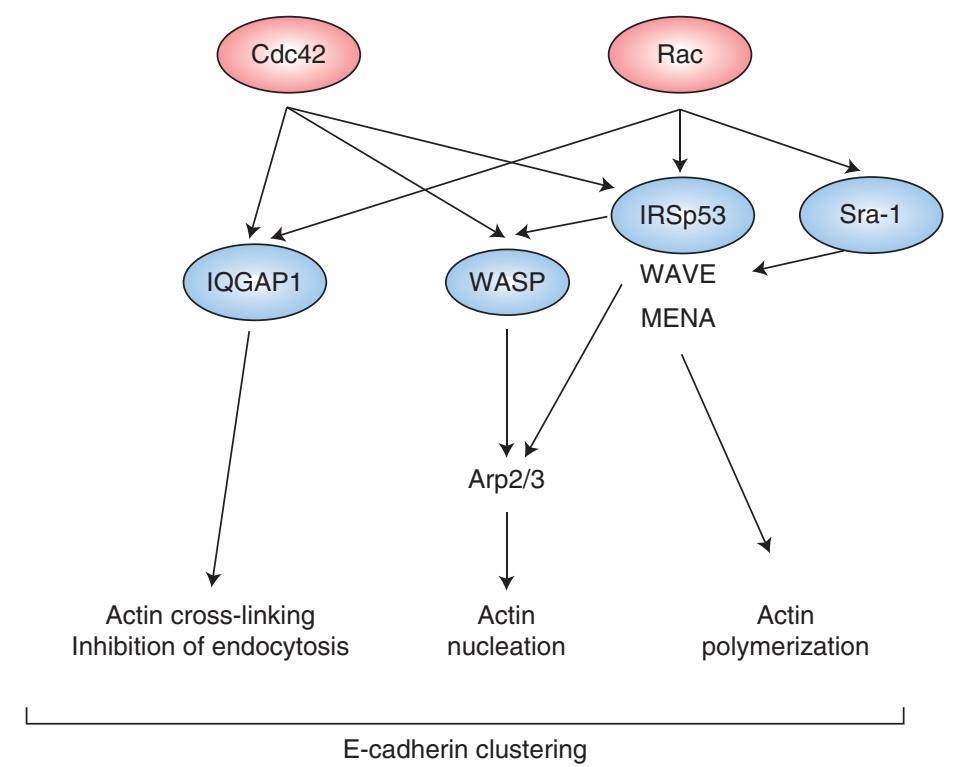

Figure 4. Possible mode of action of activated Rac1 and Cdc42 for E-cadherin-mediated adhesions. Activated Cdc42 induces actin nucleation through WASP and the Arp2/3 complex. Acting through WAVEs, Rac1 enhances actin polymerization locally at sites of E-cadherin-mediated adhesions. This results in the local remodeling of actin filaments near the Rac1/Cdc42-activated membrane. In addition, IQGAP1, an effector of Rac1 and Cdc42, positively regulates E-cadherin-dependent intercellular adhesions through cross-linking actin filaments as well as inhibiting of E-cadherin endocytosis.

required for E-cadherin-mediated cell-cell adhesions in MDCKII cells.

Those studies indicate that Rho family GTPases control cadherin-mediated cell-cell adhesions. More direct evidence was obtained using a quantitative, cell-dissociation assay for E-cadherin activity. These experiments sought to determine whether Rho family GTPases regulate cadherin-mediated cell-cell adhesions by acting on either the cadherincatenin complex or the actin cytoskeleton and other components. Two stable cell lines derived from mouse L fibroblasts, which lack cadherin, are used: (1) EL cells express wildtype E-cadherin; (2) $\mathrm{nE} \alpha \mathrm{CL}$ cells express an E-cadherin mutant in which the distal $\beta$-catenin binding is replaced by the carboxyterminal domain of $\alpha$-catenin, thereby preventing remodeling of the cadherin-catenin complex. Although both cell lines adhere to each other in an E-cadherin-dependent manner, cell-cell adhesions in nEaCL cells do not require the distal $\beta$-catenin-binding domain of E-cadherin, $\beta$-catenin, or the amino terminus of $\alpha$-catenin. The cadherin-catenin complex in $\mathrm{nE} \alpha \mathrm{CL}$ cells is not remodeled (Nagafuchi et al. 1994). The expression of Rac1N17 or dominant-negative Cdc42 (Cdc42N17) in EL cells markedly reduces E-cadherin activity, whereas expression of Rac1N17 or Cdc42N17 in nE $\alpha$ CL cells hardly reduces mutant E-cadherin activity (Fukata et al. 1999). This observation indicates that Rac1 and Cdc42 regulate E-cadherin activity through the cadherin-catenin complex. On the other hand, the expression of dominantnegative RhoA (RhoAN19) slightly reduces E-cadherin activity in both EL cells and $\mathrm{nE} \alpha \mathrm{CL}$ cells, suggesting that RhoA affects E-cadherin-mediated adhesive activity (presumably through the actin cytoskeleton or other components) but does not affect the cadherin-catenin complex.

How Rho family GTPases control Ecadherin-mediated intercellular adhesions remains an interesting question. One of the 
explanations involves the coordination of downstream effectors (Fig. 4). IQGAP1, an effector of Rac1 and Cdc42, has been implicated in E-cadherin-mediated intercellular adhesions. IQGAP1 has actin-cross-linking activity that is enhanced by activated Racl/ Cdc42. IQGAP1 localizes to sites of cell-cell contact in epithelial cells and can associate with $\beta$-catenin in vivo and in vitro (Kuroda et al. 1998). When overexpressed in EL cells, IQGAP1 interacts with $\beta$-catenin and induces the dissociation of $\alpha$-catenin from $\beta$-catenin. This, in turn, weakens E-cadherin-mediated intercellular adhesions. When the amount of activated Racl increases, Racl interacts with IQGAP1, thereby stabilizing actin filaments. Under these conditions, IQGAP1 does not bind to $\beta$-catenin and cannot dissociate $\alpha$-catenin from the cadherin-catenin complex, leading to strong adhesions. In contrast, when the amount of inactivated Racl increases, IQGAP1 is freed from Racl and interacts with $\beta$-catenin to dissociate $\alpha$-catenin from the cadherin-catenin complex, resulting in weak adhesions (Noritake et al. 2005). Because IQGAP1 has anti-GTPase activity (Hart et al. 1996), it is possible that IQGAP1 controls the amount of GTP-bound Racl at sites of cellcell contacts and leads to stable adhesions (Noritake et al. 2005). Furthermore, it has been shown that the inhibition of transinteraction E-cadherin endocytosis is mediated by the reorganization of the actin cytoskeleton by the IQGAP1-Rac/Cdc42 complex (Izumi et al. 2004). Thus, IQGAP1 behaves as a positive and negative regulator of cell-cell adhesion downstream of Racl.

The actin polymerization machinery is another mediator between Racl activation and E-cadherin-mediated cell-cell adhesion (Fig. 4). Recruitment and activation of Racl and Cdc42 by homophilic E-cadherin ligations can induce actin polymerization through the Arp $2 / 3$ complex and WAVEs or WASP. Together with other actin-binding proteins such as cortactin, polymerized actin filaments reinforce cadherin-mediated adhesions (Gates and Peifer 2005; Scott and Yap 2006; Vasioukhin and Fuchs 2001). Significantly, inhibition of Rac1 signaling blocks actin assembly at sites of cell-cell adhesion (Braga et al. 1997; Takaishi et al. 1997). It is interesting to note that Racl also functions in the clustering of integrin receptors, suggesting that it could play a similar role in the clustering of E-cadherin. However, the effect of constitutively active Racl on adherens junctions depends on the cell type. In keratinocytes, constitutively active Rac1 (Rac1L61) causes the disassembly of adherens junctions (Braga et al. 2000), which is opposite to what is observed in MDCKII cells (see previous). The molecular mechanisms underlying these cell type-dependent effects need to be clarified.

Downstream signaling pathways that mediate the effects of RhoA on adherens junctions remain largely unknown. In keratinocytes, adherens junction formation has been shown to depend on the activity of the tyrosine kinase Fyn (Calautti et al. 2002). Constitutively active RhoA (RhoAV14) stimulates Fynmediated tyrosine phosphorylation of catenins and cell-cell adhesions, indicating that Fyn and possibly other Src family kinases can function downstream of RhoA in the establishment of adherens junctions. As described previously, during the establishment of cell-cell adhesions, RhoA is activated at the most distal edges of the expanding cell-cell contacts along with phosphorylated myosin II (Yamada and Nelson 2007). Rho-kinase, an effector of RhoA, directly phosphorylates myosin light chain and myosin phosphatase target subunit-1 and inhibits myosin phosphatase activity (Kaibuchi et al. 1999). This results in an increase in myosin light chain phosphorylation and subsequent actomyosin contraction (Kaibuchi et al. 1999). E-cadherin-mediated activation of RhoA is likely involved in the expansion of cell-cell adhesions through Rho-kinase.

Activated Rho family GTPases affect the surface level of E-cadherin expression, presumably by regulating endocytic transport (Mosesson et al. 2008). Constitutively active Rac1 (Rac1L61) and RhoA (RhoAL63) inhibit clathrin-dependent endocytosis in fibroblasts (Lamaze et al. 1996). This raises the possibility that Rho family GTPases could regulate 
cadherin-mediated cell-cell adhesions by controlling cadherin transport. Indeed, Rac1V12 and RhoAV14 inhibit HGF- and TPA-induced endocytosis of cadherin in MDCKII cells (Kamei et al. 1999). However, microinjection of Rac1L61 in keratinocytes causes E-cadherin to relocalize in large intracellular vesicles via a clathrin-independent pathway and disrupts cell-cell contacts. This discrepancy may be because of differences in cell types or levels of Racl activity (Braga et al. 2000; Braga et al. 1999). Regardless, the molecular mechanisms by which Racl and RhoA regulate the endocytosis of E-cadherin remains to be clarified.

The first evidence indicating that Rap1 is required for cell-cell junctions came from genetic studies in Drosophila melanogaster (Knox and Brown 2002). In MDCKII cells, Rap1 activity is required not only for $\mathrm{Cdc} 42$ activation during cell-cell junction formation but also for maintaining E-cadherin-mediated cell-cell adhesions (Fukuyama et al. 2005; Hogan et al. 2004). "Fast cycling" constitutively active Cdc42 (Cdc42L28) can rescue the effects of Rap1GAP on cell-cell junction formation. Furthermore, as described previously, activation of Rap1 by nectins is required for the subsequent activation of $\mathrm{Cdc} 42$ and Racl. Thus, one of the functions of Rap1 activation may be the recruitment of Racl and Cdc42 GEFs to the site of initial cell-cell contacts to provide a link with the actin cytoskeleton. In addition, Rap1 may also be involved in the recruitment of junctional proteins. One protein heavily involved in this process is afadin/AF6, an effector of Rap1. In vitro studies show that afadin/AF6 in the presence of Rap1 inhibits the endocytosis of E-cadherins that are not engaged in homophilic transinteractions (Hoshino et al. 2005). Furthermore, strong activation of Rap1 occurs on adherens junction disassembly triggered by E-cadherin internalization and trafficking in the endocytic pathway (Retta et al. 2006). Such internalized E-cadherin is colocalized with Rap1 at the perinuclear Rab11-positive recycling endosome compartment, and Rap1 associates with a subset of E-cadherin-catenin complexes lacking p120ctn. Although the mode of action of Rap1 at the cell-cell adhesions remains largely unknown, Rap1 appears to act as a critical regulator of E-cadherinmediated intercellular adhesion.

Recent evidence indicates that the Rab and Arf family of small GTPases are critical regulators that control the surface level of E-cadherin. Even in confluent cells, E-cadherin undergoes continuous endocytosis and exocytosis. The majority of studies implicates a clathrin-dependent route of E-cadherin internalization (Kimura et al. 2006), whereas some suggest the existence of non-clathrindependent pathways (e.g., caveola-mediated endocytosis) ( $\mathrm{Lu}$ et al. 2003) and an EGFinduced macropinocytosis pathway (Bryant et al. 2007). Important mechanisms controlling E-cadherin endocytosis involve binding of p120ctn to the juxtamembrane domain of E-cadherin, and the tyrosine phosphorylation of E-cadherin by receptor tyrosine kinases and Src family kinases (Mellman and Nelson 2008; Mosesson et al. 2008).

The intracellular fate of internalized Ecadherin (i.e., sorting for degradation or recycling) is crucial, as it eliminates existing junctions or re-deploys E-cadherin to new junctions. Along with constitutive clathrinmediated endocytosis, cadherin internalization is selectively induced by growth factors. The recycling endosome serves as a major location of cadherin for sorting back to the plasma membrane. Arf6, an endosomal GTPbinding protein, regulates cadherin endocytosis in response to EGF. Rab4 and Rab11 on the recycling endosomes also participate in E-cadherin endocytosis. Activated Rab4 interacts within the trans-Golgi network, whereas Rab11 seems to regulate not only the delivery of nascent E-cadherin from the Golgi to the basolateral surface but also the ability of internalized E-cadherin to activate Rap1 while residing in recycling endosomes (Balzac et al. 2005). Mechanisms that regulate the surface level of E-cadherin expression have begun to be uncovered. It will be worthwhile for future studies to reveal the functional cross talk among small GTPases in this process. 
T. Watanabe, K. Sato, and K. Kaibuchi

\section{CONCLUDING REMARKS}

Small GTPases have emerged as key players mediating the effects of signals, from cadherin engagement to downstream cellular machines that control the organization of the actin cytoskeleton, contractility, and vesicle trafficking. The identification and characterization of effectors for small GTPases have unraveled the action of small GTPases, especially those with relevance to the actin cytoskeleton, in E-cadherin-mediated intercellular adhesions. It is worthwhile in the future to examine in more detail the molecular mechanisms that control E-cadherin trafficking in the maintenance of intercellular adhesions. In contrast, much less is known about the signaling mechanisms that translate cadherin-mediated cues into spatio-temporal regulation of the small GTPases. It is likely, however, that the concerted action of GEFs and GAPs is critical for the precisely timing and localized activation of small GTPases.

\section{REFERENCES}

Adams CL, Nelson WJ. 1998. Cytomechanics of cadherinmediated cell-cell adhesion. Current Opinion Cell Biol 10: $572-577$.

Akhtar N, Hotchin NA. 2001. RAC1 regulates adherens junctions through endocytosis of E-cadherin. Mol Biol Cell 12: 847-862.

Anastasiadis PZ. 2007. p120-ctn: A nexus for contextual signaling via Rho GTPases. Biochim Biophys Acta 1773: 34-46.

Balzac F, Avolio M, Degani S, Kaverina I, Torti M, Silengo L, Small JV, Retta SF. 2005. E-cadherin endocytosis regulates the activity of Rap1: A traffic light GTPase at the crossroads between cadherin and integrin function. J Cell Sci 118: $4765-4783$.

Betson M, Lozano E, Zhang J, Braga VM. 2002. Rac activation upon cell-cell contact formation is dependent on signaling from the epidermal growth factor receptor. J Biol Chem 277: 36962-36969.

Blanpain C, Fuchs E. 2009. Epidermal homeostasis: A balancing act of stem cells in the skin. Nat Rev Mol Cell Biol 10: 207-217.

Braga VM. 2002. Cell-cell adhesion and signalling. Current Opinion Cell Biol 14: 546-556.

Braga VM, Yap AS. 2005. The challenges of abundance: Epithelial junctions and small GTPase signalling. Current Opinion Cell Biol 17: 466-474.

Braga VM, Betson M, Li X, Lamarche-Vane N. 2000. Activation of the small GTPase Rac is sufficient to disrupt cadherin-dependent cell-cell adhesion in normal human keratinocytes. Mol Biol Cell 11: 3703-3721.

Braga VM, Del Maschio A, Machesky L, Dejana E. 1999. Regulation of cadherin function by Rho and Rac: Modulation by junction maturation and cellular context. Mol Biol Cell 10: 9-22.

Braga VM, Machesky LM, Hall A, Hotchin NA. 1997. The small GTPases Rho and Rac are required for the establishment of cadherin-dependent cell-cell contacts. J Cell Biol 137: $1421-1431$.

Bryant DM, Kerr MC, Hammond LA, Joseph SR, Mostov KE, Teasdale RD, Stow JL. 2007. EGF induces macropinocytosis and SNX1-modulated recycling of E-cadherin. J Cell Sci 120: 1818-1828.

Bustos RI, Forget MA, Settleman JE, Hansen SH. 2008. Coordination of Rho and Rac GTPase function via p190B RhoGAP. Current Biol 18: 1606-1611.

Calautti E, Grossi M, Mammucari C, Aoyama Y, Pirro M, Ono Y, Li J, Dotto GP. 2002. Fyn tyrosine kinase is a downstream mediator of Rho/PRK2 function in keratinocyte cell-cell adhesion. J Cell Biol 156: 137-148.

Delva E, Tucker DK, Kowalczyk AP. 2009. The desmosome. Cold Spring Harb Perspect Biol 1: a002543.

Dobrosotskaya IY, James GL. 2000. MAGI-1 interacts with $\beta$-catenin and is associated with cell-cell adhesion structures. Biochem Biophys Res Comm 270: 903-909.

Espada J, Perez-Moreno M, Braga VM, Rodriguez-Viciana P, Cano A. 1999. H-Ras activation promotes cytoplasmic accumulation and phosphoinositide $3-\mathrm{OH}$ kinase association of $\beta$-catenin in epidermal keratinocytes. J Cell Biol 146: $967-980$.

Fleming IN, Elliott CM, Exton JH. 1996. Differential translocation of rho family GTPases by lysophosphatidic acid, endothelin-1, and platelet-derived growth factor. J Biol Chem 271: 33067-33073.

Fukata M, Kaibuchi K. 2001. Rho-family GTPases in cadherin-mediated cell-cell adhesion. Nat Rev Mol Cell Biol 2: 887-897.

Fukata M, Kuroda S, Nakagawa M, Kawajiri A, Itoh N, Shoji I, Matsuura Y, Yonehara S, Fujisawa H, Kikuchi A, et al. 1999. Cdc42 and Racl regulate the interaction of IQGAP1 with $\beta$-catenin. $J$ Biol Chem 274: 26044-26050.

Fukuhara S, Murga C, Zohar M, Igishi T, Gutkind JS. 1999. A novel PDZ domain containing guanine nucleotide exchange factor links heterotrimeric $\mathrm{G}$ proteins to Rho. J Biol Chem 274: 5868-5879.

Fukuhara T, Shimizu K, Kawakatsu T, Fukuyama T, Minami Y, Honda T, Hoshino T, Yamada T, Ogita H, Okada M, et al. 2004. Activation of Cdc42 by trans interactions of the cell adhesion molecules nectins through c-Src and Cdc42-GEF FRG. Journal of Cell Biology 166: 393-405.

Fukuyama T, Ogita H, Kawakatsu T, Fukuhara T, Yamada T, Sato T, Shimizu K, Nakamura T, Matsuda M, Takai Y. 2005. Involvement of the c-Src-Crk-C3G-Rap1 signaling in the nectin-induced activation of Cdc42 and formation of adherens junctions. J Biol Chem 280: 815-825.

Furuse M. 2009. Molecular basis of the core structure of tight junctions. Cold Spring Harb Perspect Biol 2: a002907. 
Gates J, Peifer M. 2005. Can 1000 reviews be wrong? Actin $\alpha$-Catenin, and adherens junctions. Cell 123: 769-772.

Goldstein B, Macara IG. 2007. The PAR proteins: Fundamental players in animal cell polarization. Develop Cell 13: 609-622.

Green KJ, Getsios S, Troyanovsky S, Godsel LM. 2009. Intercellular junction assembly, dynamics and homeostasis. Cold Spring Harb Perspect Biol 2: a000125.

Gulli MP, Peter M. 2001. Temporal and spatial regulation of Rho-type guanine-nucleotide exchange factors: The yeast perspective. Genes Develop 15: 365-379.

Gumbiner BM. 2000. Regulation of cadherin adhesive activity. J Cell Biol 148: 399-404.

Halbleib JM, Nelson WJ. 2006. Cadherins in development: Cell adhesion, sorting, and tissue morphogenesis. Genes Develop 20: 3199-3214.

Hart MJ, Callow MG, Souza B, Polakis P. 1996. IQGAP1, a calmodulin-binding protein with a rasGAP-related domain, is a potential effector for cdc42Hs. EMBO J 15: 2997-3005.

Hartsock A, Nelson WJ. 2008. Adherens and tight junctions: Structure, function and connections to the actin cytoskeleton. Biochim Biophys Acta 1778: 660-669.

Hogan C, Serpente N, Cogram P, Hosking CR, Bialucha CU, Feller SM, Braga VM, Birchmeier W, Fujita Y. 2004. Rap1 regulates the formation of E-cadherin-based cell-cell contacts. Mol Cell Biol 24: 6690-6700.

Hoshino T, Sakisaka T, Baba T, Yamada T, Kimura T, Takai Y. 2005. Regulation of E-cadherin endocytosis by nectin through afadin, Rap1, and p120ctn. J Biol Chem 280: 24095-24103.

Hoshino M, Sone M, Fukata M, Kuroda S, Kaibuchi K, Nabeshima Y, Hama C. 1999. Identification of the stef gene that encodes a novel guanine nucleotide exchange factor specific for Racl. J Biol Chem 274: 17837-17844.

Ide N, Hata Y, Deguchi M, Hirao K, Yao I, Takai Y. 1999. Interaction of S-SCAM with neural plakophilin-related Armadillo-repeat protein/delta-catenin. Biochem Biophys Res Comm 256: 456-461.

Izumi G, Sakisaka T, Baba T, Tanaka S, Morimoto K, Takai Y. 2004. Endocytosis of E-cadherin regulated by Rac and Cdc42 small G proteins through IQGAP1 and actin filaments. J Cell Biol 166: 237-248.

Jaffe AB, Hall A. 2005. Rho GTPases: Biochemistry and biology. Ann Rev Cell Develop Biol 21: 247-269.

Jou TS, Nelson WJ. 1998. Effects of regulated expression of mutant RhoA and Rac1 small GTPases on the development of epithelial (MDCK) cell polarity. J Cell Biol 142: 85-100.

Kaibuchi K, Kuroda S, Amano M. 1999. Regulation of the cytoskeleton and cell adhesion by the Rho family GTPases in mammalian cells. Ann Rev Biochem 68: 459-486.

Kamei T, Matozaki T, Sakisaka T, Kodama A, Yokoyama S, Peng YF, Nakano K, Takaishi K, Takai Y. 1999. Coendocytosis of cadherin and c-Met coupled to disruption of cell-cell adhesion in MDCK cells-regulation by Rho, Rac and Rab small G proteins. Oncogene 18: 6776-6784.
Kawajiri A, Itoh N, Fukata M, Nakagawa M, Yamaga M, Iwamatsu A, Kaibuchi K. 2000. Identification of a novel $\beta$-catenin-interacting protein. Biochem Biophys Res Commun 273: 712-717.

Kawakatsu T, Ogita H, Fukuhara T, Fukuyama T, Minami Y, Shimizu K, Takai Y. 2005. Vav2 as a Rac-GDP/GTP exchange factor responsible for the nectin-induced, c-Src- and Cdc42-mediated activation of Rac. J Biol Chem 280: 4940-4947.

Kawakatsu T, Shimizu K, Honda T, Fukuhara T, Hoshino T, Takai Y. 2002. Trans-interactions of nectins induce formation of filopodia and Lamellipodia through the respective activation of $\mathrm{Cdc} 42$ and Rac small $\mathrm{G}$ proteins. J Biol Chem 277: 50749-50755.

Kim SH, Li Z, Sacks DB. 2000. E-cadherin-mediated cell-cell attachment activates Cdc42. J Biol Chem 275: 36999-37005.

Kimura T, Sakisaka T, Baba T, Yamada T, Takai Y. 2006. Involvement of the Ras-Ras-activated Rab5 guanine nucleotide exchange factor RIN2-Rab5 pathway in the hepatocyte growth factor-induced endocytosis of E-cadherin. J Biol Chem 281: 10598-10609.

Kiyokawa E, Hara S, Nakamura T, Matsuda M. 2006. Fluorescence (Forster) resonance energy transfer imaging of oncogene activity in living cells. Cancer Sci 97: 8-15.

Knox AL, Brown NH. 2002. Rap1 GTPase regulation of adherens junction positioning and cell adhesion. Science 295: 1285-1288.

Kooistra MR, Dube N, Bos JL. 2007. Rap1: A key regulator in cell-cell junction formation. J Cell Sci 120: 17-22.

Kotani K, Yonezawa K, Hara K, Ueda H, Kitamura Y, Sakaue H, Ando A, Chavanieu A, Calas B, Grigorescu F, et al. 1994. Involvement of phosphoinositide 3-kinase in insulin- or IGF-1-induced membrane ruffling. EMBO J 13: 2313-2321.

Kourlas PJ, Strout MP, Becknell B, Veronese ML, Croce CM, Theil KS, Krahe R, Ruutu T, Knuutila S, Bloomfield CD, et al. 2000. Identification of a gene at 11q23 encoding a guanine nucleotide exchange factor: Evidence for its fusion with MLL in acute myeloid leukemia. Proc Natl Acad Sci 97: 2145-2150.

Kovacs EM, Ali RG, McCormack AJ, Yap AS. 2002. E-cadherin homophilic ligation directly signals through Rac and phosphatidylinositol 3-kinase to regulate adhesive contacts. J Biol Chem 277: 6708-6718.

Kozma R, Sarner S, Ahmed S, Lim L. 1997. Rho family GTPases and neuronal growth cone remodelling: Relationship between increased complexity induced by $\mathrm{Cdc} 42 \mathrm{Hs}$, Racl, and acetylcholine and collapse induced by RhoA and lysophosphatidic acid. Mol Cell Biol 17: 1201-1211.

Kranenburg O, Poland M, Gebbink M, Oomen L, Moolenaar WH. 1997. Dissociation of LPA-induced cytoskeletal contraction from stress fiber formation by differential localization of RhoA. J Cell Sci 110: 2417-2427.

Kroschewski R, Hall A, Mellman I. 1999. Cdc42 controls secretory and endocytic transport to the basolateral plasma membrane of MDCK cells. Nat Cell Biol 1: $8-13$. 
Kuroda S, Fukata M, Nakagawa M, Fujii K, Nakamura T, Ookubo T, Izawa I, Nagase T, Nomura N, Tani H, et al. 1998. Role of IQGAP1, a target of the small GTPases Cdc42 and Racl, in regulation of E-cadherin-mediated cell-cell adhesion. Science 281: 832-835.

Lamaze C, Chuang TH, Terlecky LJ, Bokoch GM, Schmid SL. 1996. Regulation of receptor-mediated endocytosis by Rho and Rac. Nature 382: 177-179.

Lu Z, Ghosh S, Wang Z, Hunter T. 2003. Downregulation of caveolin-1 function by EGF leads to the loss of E-cadherin, increased transcriptional activity of $\beta$-catenin, and enhanced tumor cell invasion. Cancer Cell 4: 499-515.

McCrea PD, Gu D, Balda M. 2009. Junctional music that the nucleus hears: Cell-cell junction signaling and the modulation of gene activity. Cold Spring Harb Perspect Biol 1: a002923.

McLachlan RW, Kraemer A, Helwani FM, Kovacs EM, Yap AS. 2007. E-cadherin adhesion activates c-Src signaling at cell-cell contacts. Mol Biol Cell 18: 3214-3223.

Mellman I, Nelson WJ. 2008. Coordinated protein sorting, targeting and distribution in polarized cells. Nat Rev Mol Cell Biol 9: 833-845.

Meng W, Takeichi M. 2009. Adherens junction: Molecular architecture and regulation. Cold Spring Harb Perspect Biol 1: a002899.

Michiels F, Habets GG, Stam JC, van der Kammen RA, Collard JG. 1995. A role for Rac in Tiam1-induced membrane ruffling and invasion. Nature 375: 338-340.

Mosesson Y, Mills GB, Yarden Y. 2008. Derailed endocytosis: An emerging feature of cancer. Nat Rev Cancer 8: 835-850.

Nagafuchi A, Ishihara S, Tsukita S. 1994. The roles of catenins in the cadherin-mediated cell adhesion: Functional analysis of E-cadherin- $\alpha$ catenin fusion molecules. J Cell Biol 127: 235-245.

Nakagawa M, Fukata M, Yamaga M, Itoh N, Kaibuchi K. 2001. Recruitment and activation of Racl by the formation of E-cadherin-mediated cell-cell adhesion sites. J Cell Sci 114: 1829-1838.

Niessen CM, Gumbiner BM. 2002. Cadherin-mediated cell sorting not determined by binding or adhesion specificity. J Cell Biol 156: 389-399.

Nimnual AS, Taylor LJ, Bar-Sagi D. 2003. Redox-dependent downregulation of Rho by Rac. Nat Cell Biol 5: 236-241.

Noren NK, Liu BP, Burridge K, Kreft B. 2000. p120 catenin regulates the actin cytoskeleton via Rho family GTPases. J Cell Biol 150: 567-580.

Noren NK, Niessen CM, Gumbiner BM, Burridge K. 2001. Cadherin engagement regulates Rho family GTPases. J Biol Chem 276: 33305-33308.

Noritake J, Watanabe T, Sato K, Wang S, Kaibuchi K. 2005. IQGAP1: A key regulator of adhesion and migration. J Cell Sci 118: 2085-2092.

Pece S, Chiariello M, Murga C, Gutkind JS. 1999. Activation of the protein kinase Akt/PKB by the formation of E-cadherin-mediated cell-cell junctions. Evidence for the association of phosphatidylinositol 3-kinase with the E-cadherin adhesion complex. J Biol Chem 274: 19347-19351.
Perego C, Vanoni C, Massari S, Longhi R, Pietrini G. 2000. Mammalian LIN-7 PDZ proteins associate with $\beta$-catenin at the cell- cell junctions of epithelia and neurons. EMBO J 19: 3978-3989.

Perez TD, Tamada M, Sheetz MP, Nelson WJ. 2008. Immediate-early signaling induced by E-cadherin engagement and adhesion. J Biol Chem 283: 5014-5022.

Perez-Moreno M, Jamora C, Fuchs E. 2003. Sticky business: Orchestrating cellular signals at adherens junctions. Cell 112: $535-548$.

Pertz O, Hahn KM. 2004. Designing biosensors for Rho family proteins-deciphering the dynamics of Rho family GTPase activation in living cells. J Cell Sci 117: 1313-1318.

Price LS, Hajdo-Milasinovic A, Zhao J, Zwartkruis FJ, Collard JG, Bos JL. 2004. Rap1 regulates E-cadherinmediated cell-cell adhesion. J Biol Chem 279: 35127 35132.

Price LS, Leng J, Schwartz MA, Bokoch GM. 1998. Activation of Rac and Cdc42 by integrins mediates cell spreading. Mol Biol Cell 9: 1863-1871.

Retta SF, Balzac F, Avolio M. 2006. Rap 1: A turnabout for the crosstalk between cadherins and integrins. Eur J Cell Biol 85: $283-293$.

Reynolds AB. 2007. p120-catenin: Past and present. Biochim Biophys Acta 1773: 2-7.

Rottner K, Hall A, Small JV. 1999. Interplay between Rac and Rho in the control of substrate contact dynamics. Current Biol 9: 640-648.

Sakurai A, Fukuhara S, Yamagishi A, Sako K, Kamioka Y, Masuda M, Nakaoka Y, Mochizuki N. 2006. MAGI-1 is required for Rap1 activation upon cell-cell contact and for enhancement of vascular endothelial cadherinmediated cell adhesion. Mol Biol Cell 17: 966-976.

Sander EE, ten Klooster JP, van Delft S, van der Kammen RA, Collard JG. 1999. Rac downregulates Rho activity: Reciprocal balance between both GTPases determines cellular morphology and migratory behavior. J Cell Biol 147: 1009-1022.

Scott JA, Yap AS. 2006. Cinderella no longer: $\alpha$-catenin steps out of cadherin's shadow. J Cell Sci 119: 4599-4605.

Shapiro L, Weis WI. 2009. Structure and biochemistry of cadherins and catenins. Cold Spring Harb Perspect Biol 1: a003053.

Takaishi K, Sasaki T, Kotani H, Nishioka H, Takai Y. 1997. Regulation of cell-cell adhesion by rac and rho small $\mathrm{G}$ proteins in MDCK cells. J Cell Biol 139: 1047-1059.

Takeichi M. 1995. Morphogenetic roles of classic cadherins. Current Opinion Cell Biol 7: 619-627.

Taya S, Inagaki N, Sengiku H, Makino H, Iwamatsu A, Urakawa I, Nagao K, Kataoka S, Kaibuchi K. 2001. Direct interaction of insulin-like growth factor-1 receptor with leukemia-associated RhoGEF. J Cell Biol 155: 809-820.

Tepass U, Truong K, Godt D, Ikura M, Peifer M. 2000. Cadherins in embryonic and neural morphogenesis. Nat Rev Mol Cell Biol 1: 91-100.

Tsukita S, Tsukita S, Nagafuchi A, Yonemura S. 1992. Molecular linkage between cadherins and actin filaments in cell-cell adherens junctions. Current Opinion Cell Biol 4: 834-839. 
Cadherin-mediated Intercellular Adhesion and Signaling Cascades

Tsukita S, Yamazaki Y, Katsuno T, Tamura A. 2008. Tight junction-based epithelial microenvironment and cell proliferation. Oncogene 27: 6930-6938.

Van Aelst L, D'souza-Schorey C. 1997. Rho GTPases and signaling networks. Genes Develop 11: 2295-2322.

Van Aelst L, Symons M. 2002. Role of Rho family GTPases in epithelial morphogenesis. Genes Develop 16: 10321054.

Vasioukhin V, Fuchs E. 2001. Actin dynamics and cell-cell adhesion in epithelia. Current Opinion Cell Biol 13: $76-84$.

Wildenberg GA, Dohn MR, Carnahan RH, Davis MA, Lobdell NA, Settleman J, Reynolds AB. 2006. p120-catenin and p190RhoGAP regulate cell-cell adhesion by coordinating antagonism between Rac and Rho. Cell 127: 1027-1039.

Wittchen ES, Worthylake RA, Kelly P, Casey PJ, Quilliam LA, Burridge K. 2005. Rap1 GTPase inhibits leukocyte transmigration by promoting endothelial barrier function. J Biol Chem 280: 11675-11682.

Yamada S, Nelson WJ. 2007. Localized zones of Rho and Rac activities drive initiation and expansion of epithelial cell-cell adhesion. J Cell Biol 178: 517-527.

Yap AS, Kovacs EM. 2003. Direct cadherin-activated cell signaling: A view from the plasma membrane. $J$ Cell Biol 160: 11-16. 


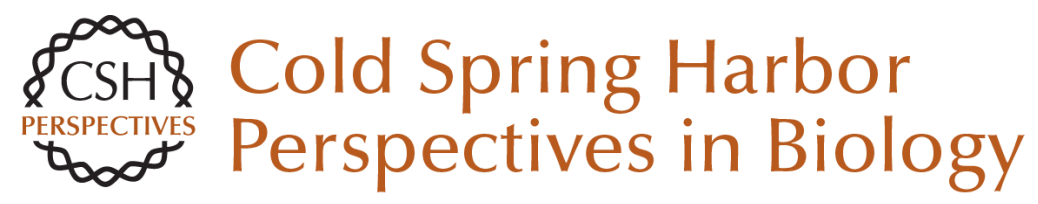

\section{Cadherin-mediated Intercellular Adhesion and Signaling Cascades Involving Small GTPases}

Takashi Watanabe, Kazuhide Sato and Kozo Kaibuchi

Cold Spring Harb Perspect Biol 2009; doi: 10.1101/cshperspect.a003020 originally published online August 12, 2009

\section{Subject Collection Cell-Cell Junctions}

Vascular Endothelial (VE)-Cadherin, Endothelial

Adherens Junctions, and Vascular Disease Maria Grazia Lampugnani, Elisabetta Dejana and Costanza Giampietro

Adherens Junctions and Desmosomes Coordinate Mechanics and Signaling to Orchestrate Tissue Morphogenesis and Function: An Evolutionary Perspective Matthias Rübsam, Joshua A. Broussard, Sara A. Wickström, et al.

Cell-Cell Contact and Receptor Tyrosine Kinase Signaling Christine Chiasson-MacKenzie and Andrea I. McClatchey

Hold Me, but Not Too Tight---Endothelial Cell-Cell Junctions in Angiogenesis

Anna Szymborska and Holger Gerhardt

Connexins and Disease Mario Delmar, Dale W. Laird, Christian C. Naus, et al.

Cell Junctions in Hippo Signaling Ruchan Karaman and Georg Halder
Signaling by Small GTPases at Cell-Cell Junctions: Protein Interactions Building Control and Networks Vania Braga

Making Connections: Guidance Cues and Receptors at Nonneural Cell-Cell Junctions lan V. Beamish, Lindsay Hinck and Timothy E. Kennedy

The Cadherin Superfamily in Neural Circuit Assembly James $D$. Jontes

Mechanosensing and Mechanotransduction at Cell-Cell Junctions Alpha S. Yap, Kinga Duszyc and Virgile Viasnoff

Beyond Cell-Cell Adhesion: Sensational

Cadherins for Hearing and Balance Avinash Jaiganesh, Yoshie Narui, Raul Araya-Secchi, et al.

Cell-Cell Junctions Organize Structural and Signaling Networks Miguel A. Garcia, W. James Nelson and Natalie Chavez

For additional articles in this collection, see http://cshperspectives.cshlp.org/cgi/collection/

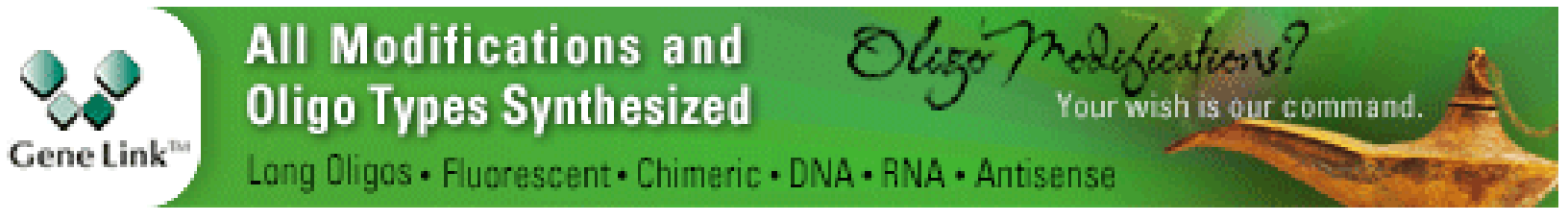


Loss of E-Cadherin-Dependent Cell-Cell Adhesion and the Development and Progression of Cancer Heather C. Bruner and Patrick W.B. Derksen

Desmosomes and Intermediate Filaments: Their Consequences for Tissue Mechanics

Mechthild Hatzfeld, René Keil and Thomas M. Magin
Cell Biology of Tight Junction Barrier Regulation and Mucosal Disease

Aaron Buckley and Jerrold R. Turner

Integration of Cadherin Adhesion and

Cytoskeleton at Adherens Junctions

René Marc Mège and Noboru Ishiyama

For additional articles in this collection, see http://cshperspectives.cshlp.org/cgi/collection/

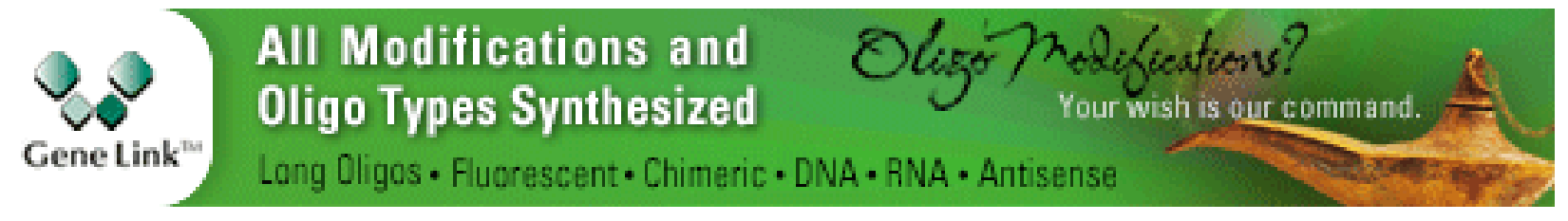

Copyright @ 2009 Cold Spring Harbor Laboratory Press; all rights reserved 